\title{
Insufficient platelet inhibition and thromboembolic complications in patients with intracranial aneurysms after stent placement
}

\author{
Hongchao Yang, MD, Youxiang Li, MD, PhD, and Yuhua Jiang, MD \\ Department of Interventional Neuroradiology, Beijing Neurosurgical Institute and Beijing Tiantan Hospital, Capital Medical \\ University, Beijing, China
}

\begin{abstract}
OBJECTIVE Insufficient platelet inhibition has been associated with an increased incidence of thromboembolic complications in cardiology patients undergoing percutaneous coronary intervention. Data regarding the relationship between insufficient platelet inhibition and thromboembolic complications in patients undergoing neurovascular procedures remain controversial. The purpose of this study was to assess the relationship of insufficient platelet inhibition and thromboembolic complications in patients with intracranial aneurysm undergoing stent treatment.
\end{abstract}

METHODS The authors prospectively recruited patients with intracranial aneurysms undergoing stent treatment and maintained the data in a database. MRI with diffusion-weighted sequences was performed within 24 hours of stent insertion to identify acute ischemic lesions. The authors used thromboelastography to assess the degree of platelet inhibition in response to clopidogrel and aspirin. Univariate and multivariate logistic regression analysis was used to identify potential risk factors of thromboembolic complications.

RESULTS One hundred sixty-eight patients with 193 aneurysms were enrolled in this study. Ninety-one of 168 (54.2\%) patients with acute cerebral ischemic lesions were identified by diffusion-weighted MRI. In $9(5.4 \%)$ patients with ischemic lesions, transient ischemic attack or stroke was found at discharge, and these complications were found in 11 (6.5\%) patients during the follow-up period. The incidence of periprocedural thromboembolic complications increased with resistance to antiplatelet agents, hypertension, hyperlipidemia, complete occlusion, and aneurysm of the anterior circulation. The multivariate regression analysis demonstrated that the anterior circulation and adenosine diphosphate (ADP) inhibition percentage were independent risk factors of perioperative thromboembolic complications. The maximum amplitude and ADP inhibition percentage were independent risk factors for thromboembolic complications during the follow-up period.

CONCLUSIONS The ADP inhibition percentage is related to thromboembolic complications after stent placement for intracranial aneurysms. The increase of the ADP inhibition may decrease the risk of thromboembolic complications.

http://thejns.org/doi/abs/10.3171/2015.6.JNS1511

KEY WORDS intracranial aneurysm; stent; cerebral infarction; antiplatelet drug resistance; platelet function test; vascular disorders

$\mathrm{C}$ EREBRAL infarction is one of the major disabling complications of neurovascular stent treatment. During the last decades, many studies have evaluated the safety and efficacy of the technique of stent placement for intracranial aneurysms, which demonstrated a range of $3.7 \%-21 \%$ thromboembolic complications. ${ }^{4,10,11,29}$

Dual antiplatelet therapy (aspirin and clopidogrel) has been used as the standard protocol to decrease the inci- dence of thromboembolic complications in patients with intracranial aneurysms undergoing stent treatment. However, many patients still experience thromboembolic complications after neurovascular intervention, despite being compliant with the standard antiplatelet medication protocol.

Previous studies have demonstrated that a low response to antiplatelet medication was associated with the

ABBREVIATIONS $\mathrm{AA}=$ arachidonic acid; $\mathrm{ADP}=$ adenosine diphosphate; $\mathrm{DWI}=$ diffusion-weighted imaging; ICA = internal carotid artery; $\mathrm{MA}=$ maximum amplitude; $\mathrm{mRS}$ = modified Rankin Scale; TEG = thromboelastography.

SUBMITTED January 3, 2015. ACCEPTED June 3, 2015

INCLUDE WHEN CITING Published online November 20, 2015; DOI: 10.3171/2015.6.JNS1511. 
increased incidence of thromboembolic complications in patients undergoing coronary stent placement or in patients with intracranial and extracranial vessel stenosis undergoing neurovascular stent placement. ${ }^{7,9,14,24}$ However, the relationship between low response to antiplatelet agents and thromboembolic complications in patients undergoing neurovascular procedures remains controversial. $^{6}$

The purpose of this study was to assess the relationship of insufficient platelet inhibition and thromboembolic complications in patients with intracranial aneurysm undergoing stent treatment.

\section{Methods \\ Patient Population}

We prospectively recruited patients with intracranial aneurysm undergoing stent treatment between September 2013 and October 2014. Informed consent was obtained from all participants and the protocol was approved by our institute. Patients older than 18 years were included. The exclusion criteria were prothrombin time $>1.5 \times$ control, thrombopenia $<80,000 / \mu l$, hematocrit $<30 \%$, contraindication to aspirin or clopidogrel, glycoprotein (GP) IIb/ IIIa inhibitor use before the procedure, severe liver insufficiency, patients with aortic arch or carotid stenosis, and unsuitability for MRI examination. The baseline information, including age, sex, medical history (hypertension, hyperlipidemia, diabetes, ischemic stroke, coronary artery disease, smoking), aneurysm characteristics (location, size, neck), occlusion grade, and stent type and number were recorded.

\section{Platelet Inhibition Test}

Baseline blood samples were drawn before the administration of dual antiplatelet therapy (aspirin and clopidogrel). The blood samples that were used to assess preoperative platelet inhibition were obtained immediately prior to the procedure. Blood samples (3-4 ml) were drawn from a single clean puncture of a forearm vein and collected in a 4-ml test tube (Becton-Dickinson) containing lithium heparin.

The platelet inhibition was tested using a thromboelastography (TEG) hemostasis system (Haemoscope Corp.). The TEG technology has been described previously.,14 Briefly, blood clot strength is measured by the amplitude of the rotation of the pin suspended into an oscillating cup that contains the blood sample. The agonists of adenosine diphosphate (ADP) or arachidonic acid (AA) are added to measure the platelet inhibition of $\mathrm{P} 2 \mathrm{Y} 12$ receptor or cyclooxygenase pathways.

The TEG percentage platelet inhibition of AA and maximum amplitude (MA)-AA (i.e., AA-induced clot strength) were used to measure the response to aspirin; the ADP percentage inhibition and MA-ADP (ADP-induced clot strength) were used to measure the response to clopidogrel. The cutoff values of AA\% $<50 \%$ and ADP\% $<30 \%$ were used to define the resistance to aspirin and clopidogrel, respectively. ${ }^{3,28}$ The MA represents the maximum amplitude with thrombin-stimulated platelets and fibrin meshwork (the maximum clot strength).

\section{Endovascular Procedures}

Patients with unruptured aneurysms were given aspirin (100 mg/day) and clopidogrel (75 mg/day) orally for 3-5 days before the procedure. As for ruptured aneurysms, a loading dose of aspirin (300 mg) and clopidogrel (300 $\mathrm{mg}$ ) was given at least 2 hours prior to the procedure. The endovascular procedure was performed under general anesthesia, and a bolus of heparin was administered using $3000 \mathrm{IU}$, then $1000 \mathrm{IU}$ every hour. Two types of stents (Enterprise [Codman Neurovascular] and Solitaire AB neurovascular remodeling device [eV3, Inc.]) were used to treat aneurysms. Daily clopidogrel $(75 \mathrm{mg})$ was maintained for 6 weeks after the procedure, and daily aspirin $(100 \mathrm{mg})$ was maintained for 6 months.

Periprocedural thromboembolic complications were evaluated by both clinical examination and MRI with diffusion-weighted imaging (MRI-DWI). A baseline 3-T MRI-DWI was performed within 1 week before the procedure, and another 3-T MRI-DWI was performed on postoperative Day 1. All MR images were reviewed by a neuroradiologist.

\section{Statistical Analysis}

Categorical variables were recorded as number (percentage), and continuous variables as the mean \pm SD. Analysis was carried out with unpaired t-tests, chi-square tests, Fisher exact tests, and logistic regression. A p value $<0.05$ was considered statistically significant (SPSS version 17.0, SPSS Inc.).

\section{Results \\ General Characteristics}

One hundred sixty-eight patients with 193 intracranial aneurysms were enrolled in this study. The mean age of the patients was $54.5 \pm 9.4$ years (range $31-76$ years), and $102(60.7 \%)$ patents were female. Fifty-three (31.5\%) patients presented with dizziness, 51 (30.4\%) with headache, $28(16.7 \%)$ with cranial nerve deficits, 19 (11.3\%) with incidentally found aneurysms, and 17 (10.1\%) with subarachnoid hemorrhage.

One hundred fifty-one (78.2\%) aneurysms were located in the anterior circulation (57 in the ophthalmic segment of the internal carotid artery (ICA), 48 in the posterior communicating artery, 15 in the middle cerebral artery, 11 in the cavernous segment of the ICA, 10 in the anterior communicating artery, 6 in the tip of the ICA, and 4 in the anterior cerebral artery), and $42(21.8 \%)$ aneurysms were located in the posterior circulation (27 in the vertebral artery, 12 in the basilar artery, and 3 in the posterior cerebral artery). The mean aneurysm size was $8.1 \pm 5.0 \mathrm{~mm}$, and the average aneurysm neck size was $4.3 \pm 2.4 \mathrm{~mm}$.

In total, 202 stents were placed in 168 patients, including 142 (70.3\%) Enterprise stents and 60 (29.7\%) Solitaire stents. In the majority of patients $(80.3 \%) 1$ stent was placed, 24 (14.3\%) patients had 2 stents, and 9 (5.4\%) patients had 3 stents.

The mean MA value was $63.4 \pm 6.0 \mathrm{~mm}$ (range 43.0$78.0 \mathrm{~mm})$. Fifty-eight $(34.5 \%)$ patients were resistant to clopidogrel, and the mean preoperative ADP inhibition percentage was $27.5 \% \pm 25.2 \%$ (range $0 \%-100 \%$ ). As for 

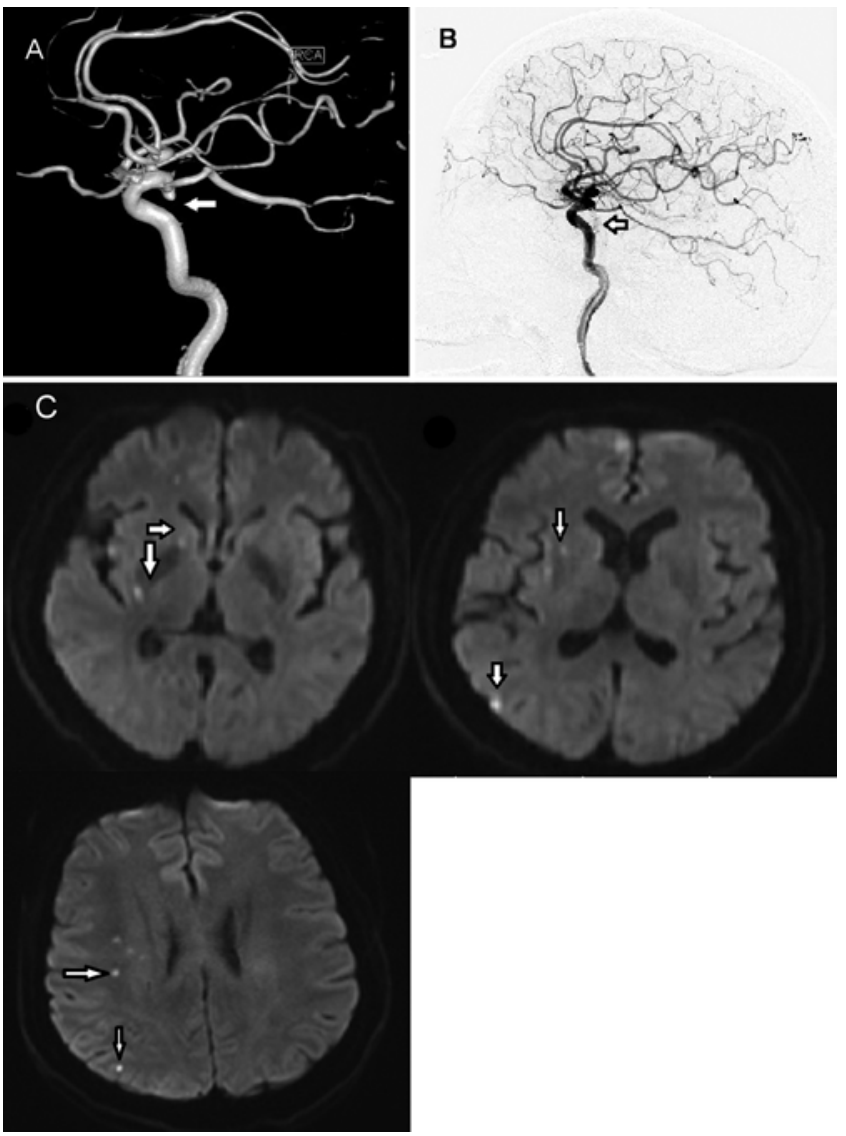

FIG. 1. A 54-year-old patient with a 10-year history of hypertension presented with a 7-year history of dizziness. The patient had resistance to clopidogrel (ADP\% 7.4\%). A: A 3D image showing a 3.3-mm right posterior communicating artery aneurysm (arrow). B: Digital subtraction angiography image obtained after the procedure showing complete occlusion of the aneurysm (arrow). C: The patient developed left hemiparesis on postoperative Day 2. Axial MRI-DWI shows multiple thromboembolic infarctions (arrows) in the right cerebral hemisphere. The patient had a permanent disabling left hemiparesis at discharge (mRS Score 3 ). aspirin, 33 (19.6\%) patients were resistant, with a mean AA inhibition percentage of $77.8 \% \pm 27.6 \%$ (range $0 \%-100 \%$ ).

All patients underwent MRI-DWI before and after the procedure, and in $91(54.2 \%)$ patients new ischemic lesions were identified. All of the ischemic lesions were located in the territory of stent-treated vessels.

Most of the perioperative thromboembolic complications were silent, but $9(5.4 \%)$ patients had ischemic clinical symptoms (6 patients had a transient neurological deficit and 3 had a permanent disability at discharge) (Fig. 1). All of these 9 patients with transient or permanent neurological deficits were resistant to clopidogrel (Table 1). Three $(1.8 \%)$ periprocedural bleeding complications occurred (2 cerebral hemorrhage events occurred during the procedure and 1 occurred on postoperative Day 1); 2 of these 3 patients had a favorable clinical outcome (modified Rankin Scale [mRS] Score 1) at discharge, and the other had a permanent neurological deficit (mRS Score 3).

\section{Comparison of Patients With and Without Perioperative Thromboembolic Complications After Stent Placement}

There were no statistical differences in age and sex between the groups of patients with and without perioperative thromboembolic complications (Table 2). Thromboembolic complications were more frequently observed in patients with aneurysms in the anterior circulation. Of patients with thromboembolic complications, 88.5\% $(92 / 104)$ of aneurysms were in the anterior circulation, compared with $66.3 \%(59 / 89)$ in patients without perioperative thromboembolic complications ( $\mathrm{p}<0.001)$.

There were more completely occluded aneurysms in the thromboembolic complications group than in the group without perioperative thromboembolic complications $(65.4 \%$ vs $48.3 \%, \mathrm{p}=0.017)$. A history of hypertension $(\mathrm{p}=0.033)$ and hyperlipidemia $(\mathrm{p}=0.03)$ were also risk factors for perioperative thromboembolic complications in univariate analysis.

The TEG test was performed in all of the enrolled pa-

TABLE 1. Characteristics of 9 patients in whom clinical ischemic events occurred after stent placement for intracranial aneurysms

\begin{tabular}{|c|c|c|c|c|c|c|c|c|c|c|}
\hline $\begin{array}{l}\text { Case } \\
\text { No. }\end{array}$ & $\begin{array}{l}\text { Age (yrs), } \\
\text { Sex }\end{array}$ & $\begin{array}{l}\text { Aneurysm } \\
\text { Size }(\mathrm{mm})\end{array}$ & $\begin{array}{l}\text { Aneurysm } \\
\text { Location }\end{array}$ & Hypertension & Hyperlipidemia & $\begin{array}{l}\text { Occlusion } \\
\text { Grade }\end{array}$ & $\begin{array}{l}\text { Event } \\
\text { Type }\end{array}$ & $\begin{array}{l}\text { Resistance } \\
\text { to Aspirin* }\end{array}$ & $\begin{array}{l}\text { Resistance to } \\
\text { Clopidogrel }^{*}\end{array}$ & $\begin{array}{l}\mathrm{mRS} \\
\text { Score }\end{array}$ \\
\hline 1 & $67, M$ & 7.0 & $\begin{array}{l}\text { Ophthalmic seg- } \\
\text { ment of ICA }\end{array}$ & Yes & Yes & Residual neck & TIA & No & Yes & 2 \\
\hline 2 & $52, F$ & 25.2 & $\begin{array}{c}\text { Cavernous seg- } \\
\text { ment of ICA }\end{array}$ & No & No & Complete & TIA & No & Yes & 1 \\
\hline 3 & $69, F$ & 11.0 & MCA & No & Yes & Complete & TIA & No & Yes & 1 \\
\hline 4 & $59, \mathrm{M}$ & 10.3 & $\begin{array}{l}\text { Ophthalmic seg- } \\
\text { ment of ICA }\end{array}$ & No & No & Complete & TIA & No & Yes & 1 \\
\hline 5 & $57, \mathrm{M}$ & 6.8 & PCA & Yes & No & Complete & TIA & No & Yes & 1 \\
\hline 6 & $55, \mathrm{~F}$ & 10.1 & $\begin{array}{l}\text { Cavernous seg- } \\
\text { ment of ICA }\end{array}$ & Yes & No & Complete & TIA & No & Yes & 1 \\
\hline 7 & $54, \mathrm{M}$ & 3.3 & PCoA & Yes & Yes & Complete & Infarction & No & Yes & 3 \\
\hline 8 & $53, \mathrm{M}$ & 5.5 & $\mathrm{BA}$ & No & No & Residual neck & Infarction & Yes & Yes & 3 \\
\hline 9 & $47, \mathrm{M}$ & 3.8 & $\begin{array}{l}\text { Ophthalmic seg- } \\
\text { ment of ICA }\end{array}$ & Yes & Yes & Complete & Infarction & No & Yes & 4 \\
\hline
\end{tabular}

$\mathrm{BA}=$ basilar artery; $\mathrm{MCA}=$ middle cerebral artery PCA = posterior cerebral artery; $\mathrm{PCoA}=$ posterior communicating artery; $\mathrm{TI} \mathrm{A}=$ transient ischemic attack.

* Antiplatelet resistance was evaluated using a TEG test. Aspirin and P2Y12 resistances were defined as aspirin and clopidogrel percentage inhibition < $50 \%$ and < $30 \%$, respectively. 
TABLE 2. Comparison of baseline characteristics and clinical variables in 168 patients with and without periprocedural thromboembolic complications*

\begin{tabular}{|c|c|c|c|}
\hline $\begin{array}{c}\text { Demographic } \\
\text { Data }\end{array}$ & $\begin{array}{c}\text { No. (\%) w/ } \\
\text { Thromboembolic } \\
\text { Complications }\end{array}$ & $\begin{array}{l}\text { No. }(\%) \text { w/o } \\
\text { Thromboembolic } \\
\text { Complications }\end{array}$ & $\begin{array}{c}\mathrm{p} \\
\text { Value }\end{array}$ \\
\hline No. of patients & $91(54.2)$ & $77(45.8)$ & \\
\hline Age in yrs & $54.8 \pm 9.2$ & $54.3 \pm 9.7$ & 0.72 \\
\hline Female & $60(65.9)$ & $42(54.5)$ & 0.13 \\
\hline \multicolumn{4}{|l|}{ Medical history } \\
\hline Hypertension & $54(59.3)$ & $33(42.9)$ & 0.033 \\
\hline Diabetes & $8(8.8)$ & $5(6.5)$ & 0.82 \\
\hline Brain ischemia & $17(18.7)$ & $9(11.7)$ & 0.21 \\
\hline Hyperlipidemia & $28(30.8)$ & $13(16.9)$ & 0.03 \\
\hline $\begin{array}{l}\text { Coronary artery } \\
\text { disease }\end{array}$ & $13(14.3)$ & $7(9.1)$ & 0.30 \\
\hline Smoking history & & & 0.97 \\
\hline Never & $56(61.5)$ & $47(61.0)$ & \\
\hline Former & $15(16.5)$ & $12(15.6)$ & \\
\hline Active & $20(22.0)$ & $18(23.4)$ & \\
\hline Rupture & $7(7.7)$ & $9(11.7)$ & 0.72 \\
\hline Aneurysm size & $7.8 \pm 4.8$ & $8.2 \pm 5.3$ & 0.53 \\
\hline Aneurysm neck & $4.1 \pm 2.1$ & $4.5 \pm 2.8$ & 0.67 \\
\hline Aneurysm location $\dagger$ & & & $<0.001$ \\
\hline Anterior circulation & $92(88.5)$ & $59(66.3)$ & \\
\hline $\begin{array}{l}\text { Posterior } \\
\quad \text { circulation }\end{array}$ & $12(11.5)$ & $30(33.7)$ & \\
\hline Occlusion grade $\dagger$ & & & 0.017 \\
\hline Complete & $68(65.4)$ & $43(48.3)$ & \\
\hline Incomplete & $36(34.6)$ & $46(51.7)$ & \\
\hline Stent‡ & & & 0.62 \\
\hline Enterprise & $75(68.8)$ & $67(72.0)$ & \\
\hline Solitaire & $34(31.2)$ & $26(28.0)$ & \\
\hline \multicolumn{4}{|l|}{ Platelet inhibition } \\
\hline MA & $63.9 \pm 6.2$ & $62.7 \pm 5.8$ & 0.24 \\
\hline AA\% inhibition & $73.7 \pm 29.8$ & $81.5 \pm 24.5$ & 0.069 \\
\hline ADP\% inhibition & $19.0 \pm 18.5$ & $37.6 \pm 28.2$ & $<0.001$ \\
\hline $\begin{array}{l}\text { Resistance to } \\
\text { aspirin }\end{array}$ & $23(25.3)$ & $11(14.3)$ & 0.077 \\
\hline $\begin{array}{r}\text { Resistance to } \\
\text { clopidogrel }\end{array}$ & $38(41.8)$ & $20(26.0)$ & 0.032 \\
\hline $\begin{array}{l}\text { * Unless otherwise indi } \\
\text { or the mean } \pm S D \text {. } \\
\dagger \text { Data represent the } n\llcorner \\
\ddagger \text { Data represent the } n \iota\end{array}$ & the values re & the number 0 & \\
\hline
\end{tabular}

tients to assess the extent of platelet inhibition by aspirin and clopidogrel. As shown in Table 2, the ADP inhibition was significantly lower in the thromboembolic complications group than in the group without thromboembolic complications $(\mathrm{p}<0.001)$. The AA inhibition was lower in the group with perioperative thromboembolic complications, but was not significantly different $(\mathrm{p}=0.069)$ (Fig. 2). The MA values were comparable in these 2 groups.
The rate of resistance to clopidogrel (ADP\% < 30\%) was significantly higher in the thromboembolic complications group $(\mathrm{p}=0.032)$.

In multiple logistic regression analysis, the anterior circulation and ADP inhibition were independent risk factors for perioperative thromboembolic complications (Table 3).

\section{Follow-Up}

A total of 166 patients $(98.8 \%)$ had clinical follow-up results (mean $7.8 \pm 2.3$ months; range 3-16 months). During the follow-up period, 2 patients experienced nonfatal intracranial hemorrhage, and 11 patients suffered thromboembolic complications related to the vascular distribution of the stent-treated parent vessel. Of the 11 patients with thromboembolic complications, 9 (81.8\%) were resistant to clopidogrel.

Univariate and multivariate logistic regression were used to analyze the factors related to thromboembolic complications during the follow-up period. The factors included age, sex, medical history, characteristics of aneurysm, occlusion results, type of stent, and platelet function test results. We found that the MA and ADP inhibition percentage were independent risk factors for thromboembolic complication (Table 4).

\section{Discussion}

The major purpose of this study was to evaluate the relationship of platelet inhibition and thromboembolic complications in patients with intracranial aneurysms undergoing stent treatment. The occurrence of thromboembolic complications was found to be associated with ADP inhibition. Patients with low ADP inhibition demonstrated a higher probability of thromboembolic complications.

Kang et al. demonstrated that a higher rate of thromboembolic complications in patients with insufficient platelet inhibition, ${ }^{20}$ which was similar to our results despite the use of a different endovascular procedure (coil vs stent) and antiplatelet function test (VerifyNow vs TEG). Light transmission aggregometry (LTA) is considered the gold standard in the evaluation of platelet function, but it is costly and time-consuming. ${ }^{25}$ Previous studies have compared LTA and other platelet function analyzers, such as VerifyNow, ${ }^{2,13}$ PFA-100, ${ }^{13}$ and TEG,, 22 and showed variable results. However, Jeong et al. demonstrated a significant correlation between TEG and LTA in 730 patients treated by percutaneous coronary intervention. ${ }^{18}$ Gurbel et al. reported that the TEG MA parameters might be better than LTA in an in vivo situation because LTA ignored the important contribution of platelet-fibrin interactions to both thrombosis and hemorrhage. ${ }^{15}$

We used TEG to test the effects of antiplatelet agents, and the proportion of resistance to clopidogrel (34.5\%) in our series was lower than that reported by Lee et al. (42.9\%) in patients tested using VerifyNow. ${ }^{21}$ Our present results showed that ADP inhibition was the independently predictive factor of ischemic lesions following stent insertion, which means that P2Y12 inhibitor resistance was associated with a higher risk of thromboembolic complications after stent placement.9,24 Similar results have also been reported in patients undergoing coronary 

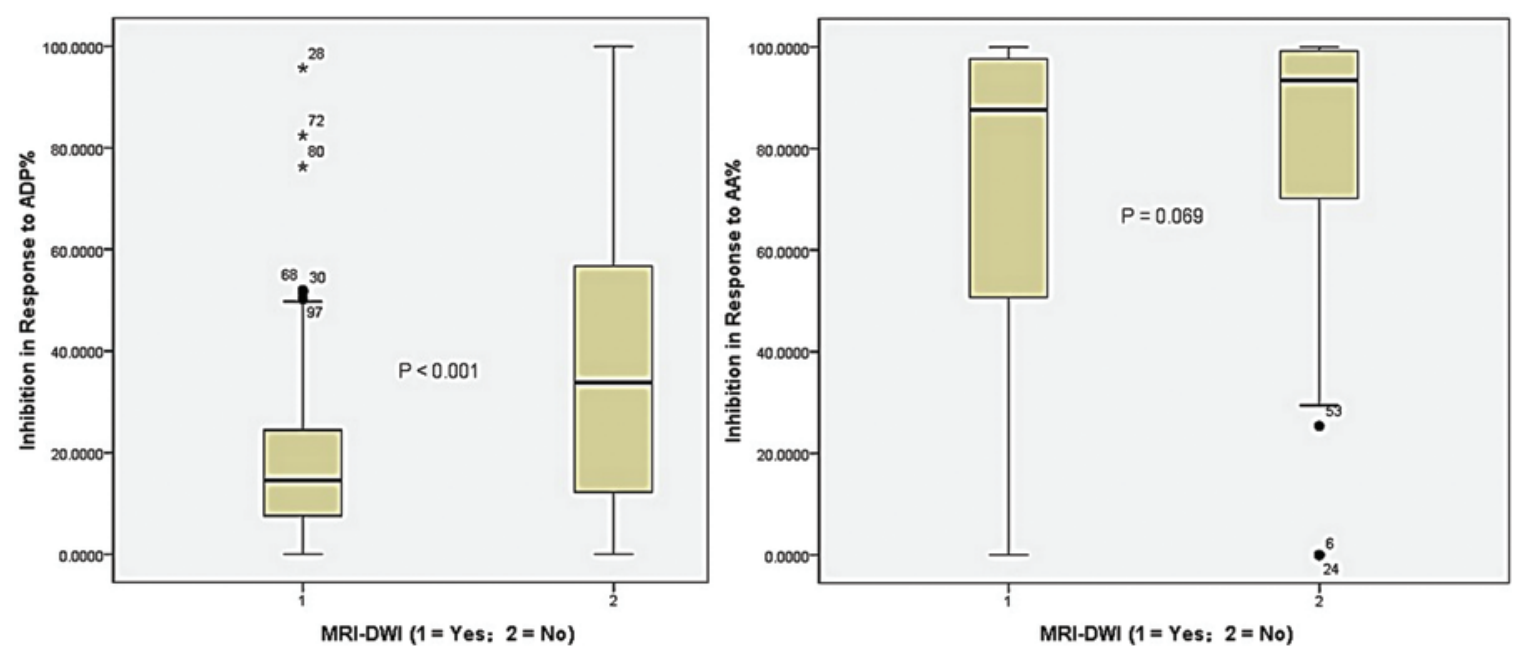

FIG. 2. Boxplots showing distribution of the percentage of $A D P$-induced (ADP\%, left) and $A A$-induced (AA\%, right) platelet inhibition tested using TEG in patients with or without cerebral infarction detected by MRI-DWI. Figure is available in color online only.

stent placement or in patients with intracranial and extracranial stenosis following stent insertion., ${ }^{7,24}$ Therefore, the ADP inhibition may be a critical factor for predicting thromboembolic complications following stent treatment, and sufficient inhibition of the platelet reactivity may reduce the occurrence of thromboembolic complications. However, sufficient inhibition of platelet reactivity may increase the risk of bleeding complications, especially for intracranial hemorrhage. Therefore, platelet inhibition must also balance the risk of thromboembolic and bleeding complications. In our previous study, we found that the TEG parameter was a predictor for acute thromboembolic complications in unruptured aneurysms undergoing stent treatment. ${ }^{30}$ More studies monitoring platelet inhibition are needed to confirm a safe range for this treatment, which may reduce the risk of thromboembolic and bleeding complications.

We chose MRI-DWI to clarify the occurrence of acute stroke because this imaging technique is highly sensitive and specific in diagnosing acute ischemic stroke. ${ }^{12,27} \mathrm{In}$ the present study, we found a $54.2 \%$ rate of periprocedural thromboembolic complications, including $5.4 \%$ of cases in which patients exhibited clinical symptoms, which was comparable with other studies. ${ }^{16,17}$ Most injuries revealed by MRI were clinically silent in our study, which might be associated with the relatively small amounts of brain affected. However, in patients with clinical syndromes, the symptoms may be caused by injuries in an eloquent region of the brain. Despite the fact that most of the thromboembolic complications were clinically silent, previous studies have demonstrated that clinically silent lesions detected by MRI-DWI might cause cognitive impairment,, 519 which needed to be confirmed by other long-term follow-up studies.

Several studies have shown the various causes of procedure-related embolic events, such as plaque cracking and migrating to distal cerebral vessels, and the stent itself causing embolism. ${ }^{1,23,26}$ All of the patients in our study presented with acute ischemic lesions in the territory of the stent-treated vessels, and one major reason may be the dislodgement of microthrombi that arose during the stent procedure.

In the current study, we demonstrated more ischemic lesions in the territory of the parent artery of the anterior circulation, which may be associated with the more complex anatomy of the anterior circulation.

Delgado et al. reported that a history of hypertension was an independent risk factor for thromboembolic complications in patients with cerebral aneurysms undergoing treatment with Pipeline stents. ${ }^{8}$ In our study, we found that a history of hypertension and hyperlipidemia were risk factors for thromboembolic complications in univariate analysis, but did not have significant difference in multivariate analysis. Hypertension and hyperlipidemia were risk factors of atherosclerosis, which implies that dislodgement of the atheroma in the procedure may be the source of embolism and cause the thromboembolic complications. However, further study is needed to verify whether preoperative control of blood pressure and blood lipid levels will decrease the rate of thromboembolic complications.

\section{Limitations of the Study}

There are several limitations in our study. First, we use only TEG to measure the resistance to antiplatelet agents

TABLE 3. Results of multivariate analysis of risk factors of periprocedural thromboembolic complications

\begin{tabular}{ccc}
\hline Variable & OR $(95 \% \mathrm{Cl})$ & p Value \\
\hline Hypertension & $1.42(0.77-2.63)$ & 0.26 \\
\hline Hyperlipidemia & $1.26(0.65-2.18)$ & 0.22 \\
\hline Occlusion grade & $1.39(0.89-2.20)$ & 0.15 \\
\hline Complete & \\
\hline Incomplete & \\
\hline Location & $4.17(1.65-10.53)$ & 0.003 \\
\hline ADP inhibition & $1.03(0.59-1.79)$ & $<0.001$ \\
\hline
\end{tabular}


TABLE 4. Risk factors for thromboembolic complications in 166 patients during the follow-up period*

\begin{tabular}{|c|c|c|c|c|c|c|c|c|}
\hline \multirow[b]{2}{*}{ Factor } & \multirow{2}{*}{$\begin{array}{c}\text { No. w/ } \\
\text { Thromboembolic } \\
\text { Complications }\end{array}$} & \multirow{2}{*}{$\begin{array}{c}\text { No. w/o } \\
\text { Thromboembolic } \\
\text { Complications }\end{array}$} & \multicolumn{2}{|c|}{$\begin{array}{c}\text { Univariate } \\
\text { Analysis }\end{array}$} & \multicolumn{3}{|c|}{$\begin{array}{c}\text { Multivariate } \\
\text { Analysis }\end{array}$} & \multirow{2}{*}{$\begin{array}{c}p \\
\text { Value }\end{array}$} \\
\hline & & & OR & $95 \% \mathrm{Cl}$ & Value & OR & $95 \% \mathrm{Cl}$ & \\
\hline No. of patients & 11 & 155 & & & & & & \\
\hline Age in yrs & $53.7 \pm 9.6$ & $54.6 \pm 9.6$ & 1.0 & $0.94-1.07$ & 0.77 & NA & NA & \\
\hline Female & $5(45.5)$ & $97(62.6)$ & 1.97 & $0.62-6.71$ & 0.34 & NA & NA & \\
\hline \multicolumn{9}{|l|}{ Medical history } \\
\hline Hypertension & $7(63.6)$ & $80(51.6)$ & 1.64 & $0.46-5.832$ & 0.44 & NA & NA & \\
\hline Diabetes & $2(18.2)$ & $11(7.1)$ & 3.22 & $0.61-16.96$ & 0.18 & NA & NA & \\
\hline Coronary artery disease & $2(18.2)$ & $18(11.6)$ & 1.69 & $0.33-8.45$ & 0.62 & NA & NA & \\
\hline Brain ischemia & $3(27.3)$ & $23(14.8)$ & 2.15 & $0.53-8.71$ & 0.38 & NA & NA & \\
\hline Hyperlipidemia & $6(54.5)$ & $36(23.2)$ & 4.11 & $1.18-14.29$ & 0.018 & 1.35 & $0.85-3.28$ & 0.65 \\
\hline Aneurysm size (mm) & $8.4 \pm 3.4$ & $8.2 \pm 4.1$ & 0.99 & $0.89-1.12$ & 0.98 & NA & NA & \\
\hline Aneurysm neck (mm) & $4.2 \pm 2.4$ & $4.3 \pm 3.6$ & 0.86 & $0.78-1.23$ & 0.71 & NA & NA & \\
\hline Aneurysm location† & & & 3.92 & $0.49-10.8$ & 0.31 & NA & NA & \\
\hline Anterior circulation & $13(92.9)$ & $136(76.8)$ & & & & & & \\
\hline Posterior circulation & $1(7.1)$ & $41(23.2)$ & & & & & & \\
\hline Rupture & $1(7.1)$ & $15(8.5)$ & 1.08 & $0.12-9.02$ & 0.94 & NA & NA & \\
\hline Occlusion grade $†$ & & & 0.98 & $0.32-2.94$ & 0.97 & NA & NA & \\
\hline Complete & $8(57.1)$ & $102(57.6)$ & & & & & & \\
\hline Incomplete & $6(42.9)$ & $75(42.4)$ & & & & & & \\
\hline Stent $¥$ & & & 0.61 & $0.21-1.82$ & 0.39 & NA & NA & \\
\hline Enterprise & $9(60)$ & $131(70.8)$ & & & & & & \\
\hline Solitaire & $6(40)$ & $54(29.2)$ & & & & & & \\
\hline \multicolumn{9}{|l|}{ Platelet function test } \\
\hline $\mathrm{MA}(\mathrm{mm})$ & $68.2 \pm 2.8$ & $65.8 \pm 3.9$ & 0.82 & $0.67-0.99$ & 0.04 & 0.842 & $0.68-0.98$ & 0.038 \\
\hline MA-ADP (mm) & $54.1 \pm 2.7$ & $44.9 \pm 12.5$ & 0.81 & $0.67-0.97$ & 0.02 & 0.763 & $0.59-0.97$ & 0.022 \\
\hline ADP $\%$ & $12.2 \pm 9.1$ & $28.6 \pm 25.6$ & 1.046 & $1.0-1.09$ & 0.051 & 1.026 & $0.97-1.07$ & 0.283 \\
\hline MA-AA (mm) & $32.2 \pm 15.5$ & $21.9 \pm 14.2$ & 0.96 & $0.92-0.99$ & 0.031 & 1.017 & $0.92-1.12$ & 0.729 \\
\hline$A A \%$ & $56.5 \pm 30.9$ & $78.7 \pm 26.9$ & 1.023 & $1.004-1.04$ & 0.016 & 1.025 & $0.97-1.07$ & 0.318 \\
\hline
\end{tabular}

$\mathrm{NA}=$ not applicable for multivariate analysis, which was performed for the factors that were significant in univariate analysis.

* Unless otherwise indicated, the values represent the number of patients (\%) or the mean \pm SD.

$\dagger$ Data represent the number of aneurysms (total 191: 2 patients with 1 aneurysm each did not have follow-up).

$\ddagger$ Data represent the number of stents (total 200: 2 patients with 1 stent each did not have follow-up).

because no other method of platelet function testing was available at our institute. Second, we could not compare the periprocedural clinical adverse events because of the low incidence.

\section{Conclusions}

Thromboembolic complications in patients with intracranial aneurysm following stent treatment were associated with ADP inhibition. Resistance to clopidogrel may increase the risk of thromboembolic complications. An adjusted antiplatelet protocol, which is based on results of the platelet function test, may reduce the rate of thromboembolic complications.

\section{References}

1. Biasi GM, Froio A, Diethrich EB, Deleo G, Galimberti S, Mingazzini P, et al: Carotid plaque echolucency increases the risk of stroke in carotid stenting: the Imaging in Carotid Angioplasty and Risk of Stroke (ICAROS) study. Circulation 110:756-762, 2004

2. Blais N, Pharand C, Lordkipanidzé M, Sia YK, Merhi Y, Diodati JG: Response to aspirin in healthy individuals. Crosscomparison of light transmission aggregometry, VerifyNow system, platelet count drop, thromboelastography (TEG) and urinary 11-dehydrothromboxane $\mathrm{B}(2)$. Thromb Haemost 102:404-411, 2009

3. Bliden KP, DiChiara J, Tantry US, Bassi AK, Chaganti SK, Gurbel PA: Increased risk in patients with high platelet aggregation receiving chronic clopidogrel therapy undergoing percutaneous coronary intervention: is the current antiplatelet therapy adequate? J Am Coll Cardiol 49:657-666, 2007

4. Chalouhi N, Jabbour P, Singhal S, Drueding R, Starke RM, Dalyai RT, et al: Stent-assisted coiling of intracranial aneurysms: predictors of complications, recanalization, and outcome in 508 cases. Stroke 44:1348-1353, 2013

5. Choi SH, Na DL, Chung CS, Lee KH, Na DG, Adair JC: Diffusion-weighted MRI in vascular dementia. Neurology 54:83-89, 2000 
6. Comin J, Kallmes DF: Platelet-function testing in patients undergoing neurovascular procedures: caught between a rock and a hard place. AJNR Am J Neuroradiol 34:730-734, 2013

7. Cuisset T, Frere C, Quilici J, Barbou F, Morange PE, Hovasse T, et al: High post-treatment platelet reactivity identified lowresponders to dual antiplatelet therapy at increased risk of recurrent cardiovascular events after stenting for acute coronary syndrome. J Thromb Haemost 4:542-549, 2006

8. Delgado Almandoz JE, Crandall BM, Scholz JM, Fease JL, Anderson RE, Kadkhodayan Y, et al: Pre-procedure P2Y12 reaction units value predicts perioperative thromboembolic and hemorrhagic complications in patients with cerebral aneurysms treated with the Pipeline Embolization Device. J Neurointerv Surg 5 (Suppl 3):iii3-iii10, 2013

9. Fifi JT, Brockington C, Narang J, Leesch W, Ewing SL, Bennet $\mathrm{H}$, et al: Clopidogrel resistance is associated with thromboembolic complications in patients undergoing neurovascular stenting. AJNR Am J Neuroradiol 34:716-720, 2013

10. Fiorella D, Albuquerque FC, Woo H, Rasmussen PA, Masaryk TJ, McDougall CG: Neuroform stent assisted aneurysm treatment: evolving treatment strategies, complications and results of long term follow-up. J Neurointerv Surg 2:16-22, 2010

11. Gentric JC, Biondi A, Piotin M, Mounayer C, Lobotesis K, Bonafé A, et al: Safety and efficacy of neuroform for treatment of intracranial aneurysms: a prospective, consecutive, French multicentric study. AJNR Am J Neuroradiol 34:1203-1208, 2013

12. Gonzalez RG, Schaefer PW, Buonanno F, Schwamm LH, Budzik RF, Rordorf G, et al: Diffusion-weighted MR imaging: diagnostic accuracy of diffusion MRI in patients scanned with 6 hours of stroke symptom onset. Radiology 210:155-162, 1999

13. Grove EL, Hvas AM, Johnsen HL, Hedegaard SS, Pedersen SB, Mortensen J, et al: A comparison of platelet function tests and thromboxane metabolites to evaluate aspirin response in healthy individuals and patients with coronary artery disease. Thromb Haemost 103:1245-1253, 2010

14. Gurbel PA, Bliden KP, Guyer K, Cho PW, Zaman KA, Kreutz $\mathrm{RP}$, et al: Platelet reactivity in patients and recurrent events post-stenting: results of the PREPARE POST-STENTING Study. J Am Coll Cardiol 46:1820-1826, 2005

15. Gurbel PA, Bliden KP, Navickas IA, Mahla E, Dichiara J, Suarez TA, et al: Adenosine diphosphate-induced plateletfibrin clot strength: a new thrombelastographic indicator of long-term poststenting ischemic events. Am Heart J 160:346-354, 2010

16. Heller RS, Dandamudi V, Lanfranchi M, Malek AM: Effect of antiplatelet therapy on thromboembolism after flow diversion with the pipeline embolization device. J Neurosurg 119:1603-1610, 2013

17. Heller RS, Miele WR, Do-Dai DD, Malek AM: Crescent sign on magnetic resonance angiography revealing incomplete stent apposition: correlation with diffusion-weighted changes in stent-mediated coil embolization of aneurysms. J Neurosurg 115:624-632, 2011

18. Jeong YH, Bliden KP, Antonino MJ, Tantry US, Gurbel PA: Usefulness of thrombelastography platelet mapping assay to measure the antiplatelet effect of P2Y(12) receptor inhibitors and high on-treatment platelet reactivity. Platelets 24:166169,2013

19. Jurga J, Nyman J, Tornvall P, Mannila MN, Svenarud P, van der Linden J, et al: Cerebral microembolism during coronary angiography: a randomized comparison between femoral and radial arterial access. Stroke 42:1475-1477, 2011

20. Kang HS, Kwon BJ, Kim JE, Han MH: Preinterventional clopidogrel response variability for coil embolization of intracranial aneurysms: clinical implications. AJNR Am J Neuroradiol 31:1206-1210, 2010

21. Lee DH, Arat A, Morsi H, Shaltoni H, Harris JR, Mawad ME: Dual antiplatelet therapy monitoring for neurointerventional procedures using a point-of-care platelet function test: a single-center experience. AJNR Am J Neuroradiol 29:1389-1394, 2008

22. Madsen EH, Saw J, Kristensen SR, Schmidt EB, Pittendreigh C, Maurer-Spurej E: Long-term aspirin and clopidogrel response evaluated by light transmission aggregometry, VerifyNow, and thrombelastography in patients undergoing percutaneous coronary intervention. Clin Chem 56:839-847, 2010

23. Markus HS, Clifton A, Buckenham T, Brown MM: Carotid angioplasty. Detection of embolic signals during and after the procedure. Stroke 25:2403-2406, 1994

24. Müller-Schunk S, Linn J, Peters N, Spannagl M, Deisenberg M, Brückmann H, et al: Monitoring of clopidogrel-related platelet inhibition: correlation of nonresponse with clinical outcome in supra-aortic stenting. AJNR Am J Neuroradiol 29:786-791, 2008

25. Nicholson NS, Panzer-Knodle SG, Haas NF, Taite BB, Szalony JA, Page JD, et al: Assessment of platelet function assays. Am Heart J 135 (5 Pt 2 Su):S170-S178, 1998

26. Rosenkranz M, Russjan A, Goebell E, Havemeister S, Thomalla G, Cheng B, et al: Carotid plaque surface irregularity predicts cerebral embolism during carotid artery stenting. Cerebrovasc Dis 32:163-169, 2011

27. Sorensen AG, Buonanno FS, Gonzalez RG, Schwamm LH, Lev MH, Huang-Hellinger FR, et al: Hyperacute stroke: evaluation with combined multisection diffusion-weighted and hemodynamically weighted echo-planar MR imaging. Radiology 199:391-401, 1996

28. Tantry US, Bliden KP, Gurbel PA: Overestimation of platelet aspirin resistance detection by thrombelastograph platelet mapping and validation by conventional aggregometry using arachidonic acid stimulation. J Am Coll Cardiol 46:17051709, 2005

29. Yahia AM, Latorre J, Gordon V, Whapham J, Malek A, Fessler RD: Thromboembolic events associated with Neuroform stent in endovascular treatment of intracranial aneurysms. J Neuroimaging 20:113-117, 2010

30. Yang H, Li Y, Jiang Y, Lv X: Thromboelastography for monitoring platelet function in unruptured intracranial aneurysm patients undergoing stent placement. Interv Neuroradiol 21:61-68, 2015

\section{Disclosures}

The authors report no conflict of interest concerning the materials or methods used in this study or the findings specified in this paper.

\section{Author Contributions}

Conception and design: Li, Jiang. Acquisition of data: Jiang. Analysis and interpretation of data: Yang. Drafting the article: Yang. Approved the final version of the manuscript on behalf of all authors: Li. Statistical analysis: Yang. Study supervision: Li.

\section{Correspondence}

Youxiang Li, Department of Interventional Neuroradiology of Beijing Neurosurgical Institute, No. 6, Tiantan West Rd., Dongcheng District, Beijing, China. email: yhchao2007@163. com. 